\title{
Pengembangan Instrumen Tes Pemecahan Masalah Bagi Mahasiswa Jurusan Fisika Pada Materi Dinamika Partikel
}

\author{
Alif Darmawan', Berlian Neno Asa', Fatah Kurniawan', Rania Nukhba', \\ Ulul Albab', Parno' \\ ${ }_{1}^{1}$ Prodi S1 Pendidikan Fisika, Universitas Negeri Malang, Malang, 65145, Indonesia \\ E-mail: ulul.albab.1703216@students.um.ac.id; parno.fmipa@um.ac.id
}

\begin{abstract}
Abstrak
Kemampuan pemecahan masalah merupakan salah satu kemampuan yang penting dimiliki oleh semua orang khususnya para mahasiswa yang sedang menempuh studi di jurusan fisika. Hal ini dikarenakan fisika merupakan ilmu yang sangat erat kaitannya dengan kehidupan sehari-hari. Sebagai mahasiswa, diperlukan adanya instrument tes yang dapat mengukur kemampuan pemecahan masalah yang dimiliki agar dapat diukur apakah kemampuan dalam proses pemecahan masalah yang dimiliki telah mencukup atau belum mencapai minimum. Telah banyak instrument tes yang dikembangkan sebagai instrument untuk mengukur kemampuan proses pemecahan masalah, tetapi seluruh instrumen yang ada dapat dikatakan kurang valid untuk mengukur kemampuan yang akan diukur. Oleh karena itu, penelitian ini difokuskan untuk mengembangkan instrumen tes kemampuan pemecahan masalah mahasiswa pada materi dinamika partikel. Hasil yang diperoleh dari penelitian ini adalah instrumen tes dinyatakan $75 \%$ hingga $100 \%$ valid oleh validator ahli serta memiliki $81,7 \%$ respons positif dari mahasiswa. Instrumen tes ini diharapkan mampu diterapkan dalam penilaian fisika serta dikembangkan pada penelitian-penelitian selanjutnya.
\end{abstract}

Kata Kunci: Dinamika partikel, Instrumen tes, Kemampuan pemecahan masalah, Mahasiswa pendidikan fisika.

\section{Development of Problem Solving Test Instrument for Undergraduate Physics Program Student on Particle Dynamics Topics}

\begin{abstract}
The ability to solve problems is one of the important abilities possessed by everyone, especially students who are studying in physics department, because physics is a science that is very closely related to daily life. As a student, there is a need for a test instrument that can measure the ability of problem solving that is owned so it can be measured whether the ability in the problem solving process is sufficient or has not reached the minimum. Many test instruments have been developed as instruments to measure the ability of the problem solving process, but all existing instruments can be said to be less valid to measure the ability to be measured. Therefore, this research is focused on developing test instruments for students' problem solving abilities on particle dynamics material. The results obtained from this study were test instruments stated $75 \%$ to $100 \%$ valid by expert validators and had $81.7 \%$ positive responses from students. This test instrument is expected to be able to be applied in physics assessment and developed in subsequent studies.
\end{abstract}

Keywords: Particle dynamics, Test instruments, Problem solving skills, Physics education student.

How to Cite: D, Alif., A, Berlian., K, Fatah., N, Rania., A, Ulul., P, Parno. (2020). Pengembangan Instrumen Tes Pemecahan Masalah Bagi Mahasiswa Jurusan Fisika Pada Materi Dinamika Partikel. Jurnal Pendidikan Fisika dan Keilmuan (JPFK), 6(1), 55-64. doi: https://doi.org/10.25273/jpfk.v6i1.5579 


\section{PENDAHULUAN}

Pemecahan masalah merupakan kegiatan yang dilakukan individu untuk menyintesis dan menerapkan kemampuan serta pengetahuan yang telah dimiliki pada situasi dan kondisi yang baru dan berbeda (Krulik \& Rudnick, 1994). Berdasarkan hal tersebut, pemecahan masalah merupakan salah satu kemampuan yang penting dikuasai oleh masing-masing individu. Perkembangan zaman yang semakin cepat, menuntut setiap individu untuk memiliki kemampuan ini agar dapat beradaptasi dengan baik. Oleh karena itu, kemampuan ini harus ditanamkan sedini mungkin agar setiap individu terbiasa melakukan pemecahan masalah secara logis.

Kemampuan memecahkan masalah merupakan sebuah kemampuan yang penting dimiliki oleh tiap individu tanpa memandang usia. Menurut Krulik and Rudnick (1994)menyatakan bahwa siswa juga sangat memerlukan kemampuan ini. Hal ini mengacu pada tuntutan untuk siswa agar memiliki kemampuan dan pengetahuan yang cukup untuk mengatasi beragam situasi, dalam hal ini merupakan situasi saat siswa harus mempelajari suatu hal baru berupa materi pelajaran dan lain-lain. Salah satu mata pelajaran yang sangat menuntut siswa untuk memiliki kemampuan pemecahan masalah yang baik adalah mata pelajaran fisika.

Kemampuan pemecahan masalah merupakan hal yang penting dalam fisika (Docktor et al., 2015; Gök \& Sýlay, 2010; Kurniawan, 2015). Fisika sangat membutuhkan kemampuan ini karena permasalahan-permasalahan dalam fisika merupakan permasalahan yang kompleks dan berkaitan dengan kehidupan seharihari. Analisis serta kemampuan diperlukan untuk mengaitkan teori yang ada dengan permasalahan yang disajikan. Kegiatan ini bertujuan untuk mendapatkan penyelesaian terbaik hingga ke inti permasalahannya. Oleh karena itu, kemampuan pemecahan masalah dapat dikatakan sebagai kemampuan yang sangat penting dimiliki selama proses pembelajaran fisika. Hal ini berkaitan dengan dengan karakter dari pembelajaran fisika yang erat kaitannya dengan kemampuan pembelajaran fisika.

Salah satu materi fisika yang sangat konkrit dan mudah sekali ditemui dalam kehidupan sehari-hari adalah materi dinamika partikel (Misbah, 2016). Materi ini meliputi kajian tentang gerak benda. Oleh karena itu, materi ini banyak ditemukan pengaplikasiannya dalam kehidupan sehari-hari. Materi ini mencakup bahasan tentang Hukum Newton 1 hingga 3. Dapat dikatakan bahwa materi ini merupakan materi dasar yang harus dipelajari sebagai pondasi awal mempelajari fisika yang berdasarkan kehidupan sehari-hari.

Materi dinamika partikel merupakan materi fundamental yang penting untuk dipelajari dan dipahami. Konsep pada dinamika partikel sangat diperlukan dalam membangun pemahaman fenomena alam sehari-hari (Council, 2012; Knight et al., 2009; Serway \& Jewett, 2004; Sornkhatha \& Srisawasdi, 2013). Fenomena alam merupakan sumber utama dalam membangun konsep dan prinsip di bidang ilmu fisika. Pemahaman konsep dinamika partikel secara baik akan menggiring mahasiswa pada pemahaman konsep mekanika secara utuh (Aini et al., 2018). Konsep mekanika inilah yang mendasari cabang-cabang fisika lainnya. Selain itu, pentingnya mempelajari dan memahami materi dinamika partikel ditunjukkan oleh maraknya penelitian mengenai analisis miskonsepsi dinamika partikel (Aini et al., 2018; Munfaridah et al., 2017) serta mengenai pengaruh model/metode/media pembelajaran tertentu terhadap pemahaman materi dinamika partikel pada peserta didik (Furwati et al., 2017; Kurniawan, 2015; Parno, 2015; Taqwa \& Rivaldo, 2019). 
Maraknya penelitian ini bukan tanpa sebab, melainkan didasari oleh kesadaran akan pentingnya dinamika partikel dalam perkembangan cabang ilmu fisika lain dan dalam kehidupan sehari-hari.

Pengukuran kemampuan pemecahan masalah mahasiswa, salah satunya dalam bentuk tes, merupakan hal yang sangat krusial. Instrumen pengukuran dalam bentuk tes yang kurang cermat akan memberikan hasil yang kurang cermat pula. Sebaliknya, teknik-teknik penyusunan tes yang tepat dapat diharapkan memberikan landasan yang kokoh untuk melakukan evaluasi yang tepat. Pada umumnya, pengembangan instrumen tes yang ada tidak mengikuti langkahlangkah penyusunan instrumen tes yang formal dan ilmiah (Sinaga, 2016). Di lain pihak, instrumen tes pemecahan masalah yang tervalidasi masih belum memadai. Pengembangan instrumen tes yang menguji kemampuan pemecahan masalah masih cukup sedikit. Penelitian pengembangan yang berkaitan dengan pemecahan masalah sudah cukup banyak, tapi tidak berfokus pada instrumen tes.

Kebanyakan penelitian pengembangan yang berkaitan dengan pemecahan masalah masih berfokus pada model pembelajaran dan media pembelajaran seperti pada penelitian Sudiarta (2007) yang mengembangkan model pembelajaran tematik berorientasi pemecahan masalah matematika dan penelitian Suarsana (2013) yang mengembangkan e-modul aljabar berorientasi pada pemecahan masalah siswa. Instrumen tes kemampuan pemecahan masalah sebenarnya sudah mulai dikembangkan, tapi instrumen ini menguji kemampuan pemecahan masalah pada materi matematika. Hal ini dapat dilihat pada penelitian Sinaga (2016) yang mengembangkan instrumen tes berbentuk soal uraian pada materi matematika kelas VIII SMP serta penelitian (Afriyanti et al., 2018; Silva et al., 2011) yang mengembangkan instrumen tes dengan soal berbasis Programme for International Students Assesment (PISA) pada materi matematika. Instrumen tes kemampuan pemecahan masalah pada materi fisika hanya dapat ditemui pada penelitian Taqwa and Rivaldo (2019) yang mengembangkan instrumen tes kemampuan pemecahan masalah pada materi listrik dinamis. Pengembangan instrumen tes pemecahan masalah pada materi dinamika partikel masih belum ada.

Banyak penelitian yang mengkaji mengenai kemampuan pemecahan masalah sehingga dibutuhkan instrumen yang valid. Dengan menggunakan isntrumen yang valid, maka pengukuran mengenai kemampuan pemecahan masalah dapat menghasilkan pengukuran yang tepat dan benar (Kurniawan \& Taqwa, 2018). Penelitian yang dilakukan Hidayat et al. (2017) merupakan pengembangan instrument tes kemampuan pemecahan masalah pada materi getaran, gelombang, dan bunyi. Selain itu untuk materi dinamika, lebih banyak pengembangan bahan ajar. Sebagaimana dalam penelitian yang telah dilakukan oleh COLLABORATIVE (2018) merupakan penelitian untuk mengembangkan emodul pada materi dinamika rotasi. Penelitian yang telah dilakukan oleh Primanda et al. (2015) adalah penelitian yang mengembangkan suplemen buku siswa untuk materi dinamika. Intrumen tes kemampuan pemecahan masalah pada materi dinamika sangat jarang ditemui. Oleh karena itu dibutuhkan intrumen tes kemampuan pemecahan masalah pada materi dinamika.

Penelitian ini mengembangkan instrument tes yang berupa soal uraian yang digunakan untuk mengukur kemampuan pemecahan masalah pada materi dinamika. Intrumen tes ini dikembangkan dengan mengadaptasi indikator pemecahan masalah (Docktor et al., 2015). Terdapat 5 indikator pemecahan 
masalah, yakni 1) useful description, 2) physics approach, 3) specific application of physics, 4) mathematical procedures, dan 5) logical progression.

Pengembangan intrumen tes ini berfokus pada materi dinamika. Hal ini didasarkan berdasarkan beberapa penelitian menunjukkan fakta bahwa masih ada kesulitan dalam materi dinamika. Sebagaimana penelitian yang telah dilakukan oleh Linuwih and Setiawan (2010) menunjukkan bahwa konsep parallel pada materi dinamika masih cenderung adanya kesalahan pada konsep yang ada. Penelitian yang dilakukan oleh (Amnirullah, 2015) menujukkan bahwa mahasiswa masih memiliki belum bisa membedakan antara dinamika translasi dan dinamika rotasi, begitu juga dengan matematis yang digunakan dalam menyelesaikan masalah. Oleh karena itu, penelitian ini bertujuan untuk mengembangkan instrumen tes kemampuan pemecahan masalah untuk mahasiswa fisika pada materi dinamika. Instrumen tes yang dikembangkan diimplementasikan untuk mengetahui kemampuan pemecahan masalah pada mahasiswa di Universitas Negeri Malang.

\section{METODE PENELITIAN}

Penelitian ini merupakan penelitian $\mathrm{RnD}$ (Research and Development) untuk mengembangkan instrument tes kemampuan pemecahan masalah menurut Branch (2010) untuk pendidik tingkat perguruan tinggi pada bab dinamika partikel. Penelitian ini dilakukan menggunakan metode ADDIE yang terdiri dari 5 tahap yaitu analisa (analyze), perencanaan (design), pengembangan (develop), Implementasi (Implement), dan evaluasi (evaluate). Dalam penelitian ini tidak dilakukan tahap keempat, yaitu implementasi. Tahap analisa dilakukan dengan mencari berbagai referensi untuk mengetahui pengembangan yang diperlukan dari instrumentinstrumen yang telah ada. Perencanaan dilakukan dengan merencanakan jenis pengembangan dan memodelkannya. Pengembangan instrument dilakukan berdasarkan rencana pengembangan yang telah dibuat. Pada tahap ini akan diperoleh data berupa skor validasi ahli serta respon mahasiswa terhadap instrument yang telah dikembangkan. Evaluasi dilakukan pada setiap tahap hingga mencapai kesimpulan akhir sesuai tujuan yaitu apakah instrument yang diteliti dan dikembangkan telah valid dan dapat mengukur kemampuan pemecahan masalah bagi calon pendidik.

Analisis validitas ahli terhadap instrument ini dilakukan dengan penghitungan persentase skor masing-masing validator dengan persamaan sebagai berikut.

Penilaian validator 1

$$
V_{\alpha 1}=\frac{T S_{e}}{T S_{\max }} \times 100 \%=\cdots \%
$$

Penilaian validator 2

$$
V_{a 2}=\frac{T S_{e}}{T S_{\max }} \times 100 \%=\cdots \%
$$

Skor total validasi ahli

$$
V_{t}=\frac{V_{a 1}-V_{a 2}}{2}=\cdots \%
$$

Dengan:

$$
\begin{aligned}
& V_{a}=\text { nilai yang diperoleh dari validator } \\
& T S_{e}=\text { total skor yang diperoleh } \\
& T S_{\max }=\text { total skor maksimum yang dapat diperoleh }
\end{aligned}
$$


$V_{t}=$ skor total validasi

Analisis validitas ahli terhadap instrument ini dilakukan dengan penghitungan persentase skor masing-masing validator dengan persamaan sebagai berikut.

Penilaian validator 1

$$
\begin{aligned}
& V_{a 1}=\frac{T S_{e}}{T S_{\max }} \times 100 \%=\cdots \% \\
& \text { Penilaian validator } 2 \\
& V_{a 2}=\frac{T S_{e}}{T S_{\max }} \times 100 \%=\cdots \%
\end{aligned}
$$

Skor total validasi ahli

$$
V_{t}=\frac{V_{a 1}-V_{a 2}}{2}=\cdots \%
$$

Dengan:

$V_{a}=$ nilai yang diperoleh dari validator

$T S_{e}=$ total skor yang diperoleh

$T S_{\max }=$ total skor maksimum yang dapat diperoleh

$V_{t}=$ skor total validasi

Data respon siswa dianalisis berdasarkan persentase untuk skala likert pada kategori respon positif dan negative. Respon negative ditunjukkan oleh skala 1 dan 2 , sementara respon positif ditunjukkan oleh skala 2 dan 4 . Penghitungan persentase dilakukan dengan persamaan sebagai berikut.

$$
\begin{aligned}
& \qquad P=\frac{f}{n} \times 100 \% \\
& \text { Dengan: } \\
& P=\text { persentase jawaban } \\
& f=\text { frekuensi jawaban } \\
& n=\text { banyak responden }
\end{aligned}
$$

\section{HASIL DAN PEMBAHASAN}

Penelitian ini bertujuan mengembangkan instrument tes pemecahan masalah dalam materi dinamika. Instrument ini berupa soal uraian dengan mengacu pada indikator pemecahan masalah yang diadaptasi dari (Docktor et al., 2015).

\section{Analisis (analyze)}

Analisis merupakan tahapan pertama dari penelitian ini. Analisis dilakukan dengan mencari artikel-artikel tentang penelitian yang pernah dilakukan mengenai pengembangan instrument pemecahan masalah. Pada tahap ini juga dilakukan analisis mengenai kekurangan-kekkurangan instrument yang telah dikembangkan serta pengembangan seperti apa yang diperlukan untuk lingkup mahasiswa. Selain itu, analisis dilanjutkan pada kondisi lingkungan tempat pengembangan dilakukan. Data yang diperoleh selama hasil analisis adalah instrument-instrumen yang telah dikembangkan untuk mengukur kemampuan pemecahan masalah masih banyak yang belum valid sehingga diperlukan pengembangan instrument hingga diperoleh hasil instrument yang valid dan siap diimplementasikan ke subjek tujuan dalam konsteks ini adalah mahasiswa. 


\section{Perencanaan (design)}

Tahap perencanaan dilakukan berdasarkan hasil yang diperoleh selama tahap analisis. Perencanaan dilakukan dengan mencari sumber-sumber soal yang memenuhi kriteria taksonomi bloom untuk proses pemecahan masalah di tingkat mahasiswa. Soal-soal yang ada dikumpulkan untuk kemudian dikembangkan sesuai dengan tujuan instrument yang dikembangkan yaitu instrument pemecahan masalah pada materi dinamika partikel. Pada tahapan ini juga disusun analisis dan pembahasan soal untuk masing-masing tahap pemecahan masalah (Docktor et al., 2015).

\section{Pengembangan (develop)}

Pada tahap pengembangan ini melaksanaan validasi ahli sebagai tahap pertama dalam pengembagan instrumen yang divalidasi oleh 2 Dosen Jurusan Fisika Universitas Negeri Malang. Pada tahap ini menggunakan validasi yang diadopsi dari Himah et al. (2017). Dengan menggunakan metode tersebut didapatkan hasil dari validator ahli pertama ditampilkan pada tabel 1. Dan validasi ahli kedua ditampilkan pada tabel 2.

Tabel 1. Hasil Validasi Ahli Pertama

\begin{tabular}{|c|c|c|c|c|c|c|}
\hline No & Indikator & Soal 1 & Soal 2 & Soal 3 & Soal 4 & Soal 5 \\
\hline 1 & Sesuai dengan indikator & $100 \%$ & $100 \%$ & $100 \%$ & $100 \%$ & $100 \%$ \\
\hline 2 & Benar secara konsep & $100 \%$ & $100 \%$ & $100 \%$ & $75 \%$ & $100 \%$ \\
\hline 3 & Kunci jawaban benar & $75 \%$ & $75 \%$ & $100 \%$ & $100 \%$ & $100 \%$ \\
\hline 4 & $\begin{array}{l}\text { Pertanyaan tidak menimbulkan tafsiran } \\
\text { ganda }\end{array}$ & $75 \%$ & $100 \%$ & $100 \%$ & $100 \%$ & $75 \%$ \\
\hline 5 & Bahasa lugas dan komunikatif & $100 \%$ & $75 \%$ & $75 \%$ & $100 \%$ & $75 \%$ \\
\hline
\end{tabular}

Tabel 2. Hasil Validasi Ahli Kedua

\begin{tabular}{lllllll}
\hline No & Indikator & Soal 1 & Soal 2 & Soal 3 & Soal 4 & Soal 5 \\
\hline $\mathbf{1}$ & Sesuai dengan indikator & $\mathbf{1 0 0 \%}$ & $\mathbf{1 0 0} \%$ & $\mathbf{1 0 0} \%$ & $\mathbf{1 0 0} \%$ & $\mathbf{1 0 0} \%$ \\
$\mathbf{2}$ & Benar secara konsep & $100 \%$ & $100 \%$ & $75 \%$ & $100 \%$ & $100 \%$ \\
$\mathbf{3}$ & Kunci jawaban benar & $100 \%$ & $75 \%$ & $100 \%$ & $100 \%$ & $100 \%$ \\
$\mathbf{4}$ & Pertanyaan tidak menimbulkan tafsiran ganda & $100 \%$ & $100 \%$ & $100 \%$ & $100 \%$ & $100 \%$ \\
$\mathbf{5}$ & Bahasa lugas dan komunikatif & $75 \%$ & $75 \%$ & $75 \%$ & $100 \%$ & $75 \%$ \\
\hline
\end{tabular}

Berdasarkan hasil dari data di atas, didapatkan total validasi dengan mengdaptasi (Himah et al., 2017). Dengan total validasi ahli didapatkan pengkategorian validitas masing-masing soal. Total validitas ahli ditampilkan pada tabel 3.

Tabel 3. Hasil Total Validasi Ahli

\begin{tabular}{|c|c|c|c|c|c|c|}
\hline No & Indikator & Soal 1 & Soal 2 & Soal 3 & Soal 4 & Soal 5 \\
\hline 1 & Sesuai dengan indikator & $100 \%$ & $100 \%$ & $100 \%$ & $100 \%$ & $100 \%$ \\
\hline 2 & Benar secara konsep & $100 \%$ & $100 \%$ & $87,5 \%$ & $87,5 \%$ & $100 \%$ \\
\hline 3 & Kunci jawaban benar & $87,5 \%$ & $75 \%$ & $100 \%$ & $100 \%$ & $100 \%$ \\
\hline 4 & Pertanyaan tidak menimbulkan tafsiran ganda & $87,5 \%$ & $100 \%$ & $100 \%$ & $100 \%$ & $87,5 \%$ \\
\hline 5 & Bahasa lugas dan komunikatif & $87,5 \%$ & $75 \%$ & $75 \%$ & $100 \%$ & $75 \%$ \\
\hline
\end{tabular}

Berdasarkan hasil dari data di atas, didapatkan informasi bahwa masingmasing soal berada pada kategori tinggi berdasarkan (Tamara \& Sunarti, 2017). Dalam proses validasi terdapat saran dari ahli, sebagaimana yang ditunjukkan tabel 4. 


\begin{tabular}{cc}
\multicolumn{2}{c}{ Tabel 4. Saran Ahli } \\
\hline Butir Soal & Saran \\
\hline $\mathbf{1 , 2}$, dan 3 & Memperbaiki bahasa soal \\
\hline $\mathbf{3}$ & $\begin{array}{c}\text { Melengkapi soal dengan }(\mathrm{g}= \\
9,8 \mathrm{~m} / \mathrm{s} 2)\end{array}$ \\
\hline $\mathbf{5}$ & Memperbaiki formulasi soal \\
\hline
\end{tabular}

\section{Evaluasi (evaluate)}

Pada tahap evaluasi, Hasil dari validasi ahli direvisi berdasarkan saran dan masukan dari ahli. Berikut contoh sebelum validasi dan setelah validasi, disajikan pada tabel 5

Tabel 5. Contoh Hasil Revisi Berdasarkan Saran Ahli

Sebelum

Andi menyusun balok $A$ dan balok $B$, seperti gambar berikut.

(a)

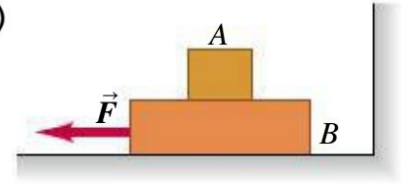

(Young \& Freedman, 2015)

Sedangkan Bandi menyusun balok $A$ dan balok $B$ seperti gambar berikut.

(b)

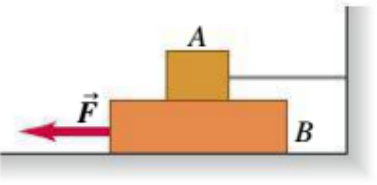

(Young \& Freedman, 2015)

Balok A memiliki berat sebesar 1,2 $\mathrm{N}$ dan balok $\mathrm{B}$ memiliki berat sebesar 3,6 N. Jika koefisien gesek kinetis pada semua permukaan sebesar 0,3 , maka bandingkan besar gaya horisontal $F \rightarrow$ pada susunan Andi dengan susunan Bandi agar balok $B$ pada masing-masing susunan bergerak dengan kelajuan konstan!

Tabel 5 menunjukkan bahwa terdapat perbaikan dari segi penyusunan gambar. Perbaikan penyusunan gambar bertujuan untuk mempermudah pembaca ketika akan menjawab persoalan berdasarkan gambar yang telah disajikan.

\section{Pengembangan (develop)}

Selain itu, tahap pengembangan juga melaksanakan penyebaran angket respons mahasiswa. Angket respons mahasiswa bertujuan untuk mengetahui kualitas bahasa dan isi soal yang akan digunakan pada instrumen tes kemampuan pemecahan masalah. Angket respons mahasiswa terdiri atas 8 item yang diadaptasi dari Usman (2017). Angket respons ini diberikan kepada 15 orang mahasiswa S1 Pendidikan Fisika Universitas Negeri Malang semester 5. Angket diisi setelah mahasiswa melihat, membaca dan memahami keseluruhan soal. Hasil analisis respons mahasiswa terhadap instrumen tes kemampuan pemecahan masalah disajikan dalam bentuk persentase sebagai berikut. 
Tabel 6. Hasil Analisis Angket Respons Mahasiswa

\begin{tabular}{clcc}
\hline Item ke- & \multicolumn{1}{c}{ Indikator } & Persentase & Respons Mahasiswa \\
\hline 1 & $\begin{array}{l}\text { Kesesuaian soal dengan materi } \\
\text { yang telah dipelajari }\end{array}$ & $85 \%$ & Positif \\
\hline 2 & $\begin{array}{l}\text { Penggunakaan bahasa } \\
\text { Indonesia yang baku dan tidak } \\
\text { ambigu }\end{array}$ & $80 \%$ & Positif \\
\hline 3 & $\begin{array}{l}\text { Kemenarikan gambar dalam } \\
\text { soal }\end{array}$ & $86,7 \%$ & Positif \\
\hline 4 & $\begin{array}{l}\text { Kejelasan petunjuk pelaksanaan } \\
\text { instrumen tes }\end{array}$ & $85 \%$ & Positif \\
\hline 5 & $\begin{array}{l}\text { Penggunaan bahasa yang } \\
\text { mudah dipahami dalam soal }\end{array}$ & $81,7 \%$ & Positif \\
\hline 6 & $\begin{array}{l}\text { Kemudahan dalam pengerjaan } \\
\text { soal }\end{array}$ & $70 \%$ & Positif \\
\hline 7 & $\begin{array}{l}\text { Kesesuaian waktu pengerjaan } \\
\text { dengan jumlah soal }\end{array}$ & $81,7 \%$ & Positif \\
\hline 8 & $\begin{array}{l}\text { Kesusaian dengan tingkat } \\
\text { kognitif mahasiswa }\end{array}$ & $83,3 \%$ & Positif \\
\hline
\end{tabular}

Berdasarkan hasil analisis yang disajikan pada Tabel 6, dapat diketahui persentase respons mahasiswa mengenai instrumen tes kemampuan pemecahan masalah yang sedang dikembangkan. Melalui tabel tersebut, didapatkan bahwa kelima butir soal mendapatkan persentase antara $70 \%$ hingga $86,7 \%$ di setiap indikatornya. Dari delapan indikator tersebut, persentase rata-rata yang didapatkan adalah sebesar $81,7 \%$. Hasil ini menunjukkan bahwa lebih dari 50\% mahasiswa memberikan respons positif. Dengan demikian berdasarkan kriteria Himah et al. (2017) dan Usman (2017), dapat disimpulkan bahwa instrumen tes kemampuan pemecahan masalah memiliki respons positif dari mahasiswa serta menunjukkan bahwa instrumen tes memenuhi kriteria tercapai tanpa revisi.

\section{KESIMPULAN}

Berdasarkan Hasil dan Pembahasan yang telah dilaksanakan sebelumnya, didapatkan simpulan sebagai berikut. Melalui uji validasi ahli, instrumen tes kemampuan pemecahan masalah dinyatakan valid dengan persentase berkisar pada $75 \%$ hingga $100 \%$ di setiap indikator. Selain itu, instrumen pemecahan masalah memiliki respons positif dari mahasiswa dengan persentase rata-rata sebesar $81,7 \%$. Dengan demikian, instrumen tes pemecahan masalah yang tengah dikembangkan telah valid dan memiliki respon positif. Diharapkan instrumen tes pemecahan masalah ini dapat diterapkan pada proses penilaian fisika dan dikembangkan melalui penelitian-penelitian selanjutnya.

\section{DAFTAR PUSTAKA}

Afriyanti, I., Wardono, W., \& Kartono, K. (2018). Pengembangan Literasi Matematika Mengacu PISA Melalui Pembelajaran Abad Ke-21 Berbasis Teknologi. PRISMA, Prosiding Seminar Nasional Matematika,

Aini, F., Taqwa, M., Saputri, D., Shodiqin, M., \& Rivaldo, L. (2018). Miskonsepsi Mahasiswa Pada Topik Gaya dan Gerak.

Amnirullah, L. (2015). Analisis Kesulitan Penguasaan Konsep Mahasiswa pada Topik Rotasi Benda Tegar Dan Momentum Sudut (halaman 34 sd 37). Jurnal Fisika Indonesia, 19(56).

Branch, R. (2010). Instructional design: The ADDIE approach. https://doi.org/10.1007/978-0-387-09506-6 
COLLABORATIVE, R. D. P. (2018). PENGEMBANGAN E-MODULE MATERI DINAMIKA ROTASI DENGAN PENDEKATAN COLLABORATIVE PROBLEM SOLVING (CPS) GUNA MENINGKATKAN KEMAMPUAN PEMECAHAN MASALAH. Prosiding Seminar Nasional Fisika (E-Journal) SNF2018 VII. https://doi.org/DOI: doi.org/10.21009/03.SNF2018.01.PE.14

Council, N. R. (2012). A framework for K-12 science education: Practices, crosscutting concepts, and core ideas. National Academies Press.

Docktor, J. L., Strand, N. E., Mestre, J. P., \& Ross, B. H. (2015). Conceptual problem solving in high school physics. Physical Review Special Topics-Physics Education Research, 11(2), 020106.

Furwati, S., Sutopo, S., \& Zubaidah, S. (2017). Peningkatan Pemahaman Konsep Hukum Newton pada Siswa SMP melalui Pembelajaran Multi Representasi. Seminar Nasional Teknologi Pembelajaran dan Pendidikan Dasar 2017,

Gök, T., \& Sýlay, I. (2010). The Effects of Problem Solving Strategies on Students' Achievement, Attitude and Motivation. Latin-American Journal of Physics Education, 4(1), 2.

Hidayat, S. R., Setyadin, A. H., Hermawan, H., Kaniawati, I., Suhendi, E., Siahaan, P., \& Samsudin, A. (2017). Pengembangan instrumen tes keterampilan pemecahan masalah pada materi getaran, gelombang, dan bunyi. Jurnal Penelitian \& Pengembangan Pendidikan Fisika, 3(2), 157-166.

Himah, F., Sudarti, S., \& Subiki, S. (2017). Pengembangan Instrumen Tes Computer Based Test-higherorder Thinking (Cbt-hot) Pada Mata Pelajaran Fisika Di SMA. Jurnal Pembelajaran Fisika, 5(1), 89-95.

Knight, R. D., Jones, B., \& Field, S. (2009). College Physics: A Strategic Approach. Pearson Education. https://books.google.co.id/books?id=PuFBPgAACAAJ

Krulik, S., \& Rudnick, J. A. (1994). Reflect... for better problem solving and reasoning. Arithmetic Teacher, 41(6), 334-339.

Kurniawan, B. R. (2015). Pengembangan Media Pembelajaran Berbasis Pendekatan Ilmiah Menggunakan Macromedia Swishmax Pada Pokok Bahasan Hukum Newton Untuk Siswa SMA Kelas X.

Kurniawan, B. R., \& Taqwa, M. R. A. (2018). Pengembangan Instrumen Tes Kemampuan Pemecahan Masalah Fisika pada Materi Listrik Dinamis. Jurnal Pendidikan: Teori, Penelitian, dan Pengembangan, 3(11), 1451-1457.

Linuwih, S., \& Setiawan, A. (2010). Latar belakang konsepsi paralel mahasiswa pendidikan fisika dalam materi dinamika. Jurnal pendidikan fisika Indonesia, $6(2)$.

Misbah, M. (2016). Identifikasi Kemampuan Pemecahan Masalah Mahasiswa Pada Materi Dinamika Partikel. Jurnal Inovasi dan Pembelajaran Fisika. https://doi.org/ https://doi.org/10.36706/jipf.v3i2.3835

Munfaridah, N., Sutopo, S., Sulur, S., \& Asim, A. (2017). ANALISIS MISKONSEPSI "GERAK DAN GAYA" MENGGUNAKAN INSTRUMEN FORCE CONCEPT INVENTORY (FCI) PADA MAHASISWA CALON GURU FISIKA. LENSA (Lentera Sains): Jurnal Pendidikan IPA, 7(2), 66-75.

Parno, P. (2015). Pengaruh Model Penemuan Terbimbing Dengan Strategi SelfExplanation Terhadap Prestasi Belajar Fisika Zat Padat Mahasiswa. Jurnal pendidikan fisika Indonesia, 11(1), 23-35.

Primanda, A., Maharta, N., \& Sesunan, F. (2015). Pengembangan Suplemen Buku Siswa Materi Dinamika Gerak dengan Pendekatan Scientific. Jurnal Pembelajaran Fisika, 3(3).

Serway, R. A., \& Jewett, J. W. (2004). Physics for Scientists and Engineers with Modern Physics: Chapters 39-46. Thomson-Brooks/Cole. https://books.google.co.id/books?id=0sMrAAAAYAAJ 
Silva, E. Y., Zulkardi, Z., \& Darmawijoyo, D. (2011). Pengembangan soal matematika model PISA pada konten uncertainty untuk mengukur kemampuan pemecahan masalah matematika siswa sekolah menengah pertama. Jurnal Pendidikan Matematika Sriwijaya, 5(1), 121685.

Sinaga, N. A. (2016). Pengembangan tes kemampuan pemecahan masalah dan penalaran matematika siswa SMP kelas VIII. PHYTHAGORAS: Jurnal Pendidikan Matematika, 11(2).

Sornkhatha, P., \& Srisawasdi, N. (2013). Supporting Conceptual Development in Newton's Laws of Motion Using an Interactive Computer-simulated Laboratory Environment. Procedia-Social and Behavioral Sciences, 93, 2010-2014.

Suarsana, I. (2013). Pengembangan e-modul berorientasi pemecahan masalah untuk meningkatkan keterampilan berpikir kritis mahasiswa. JPI (Jurnal Pendidikan Indonesia), 2(2).

Sudiarta, I. G. P. (2007). Pengembangan Pembelajaran Berpendekatan Tematik Berorientasi Pemecahan Massalah Matematika Terbuka untuk Mengembangkan Kompetensi Berpikr Divergen, Kritis dan Kreatif. Jurnal Pendidikan dan Kebudayaan, 13(69), 1004-1024.

Tamara, A. F., \& Sunarti, T. (2017). Penerapan model pembelajaran guided inquiry untuk meningkatkan kemampuan literasi sains siswa pada materi elastisitas di SMAN 1 Plemahan Kediri. Jurnal Inovasi Pendidikan Fisika, 6(3), 1-5.

Taqwa, M. R. A., \& Rivaldo, L. (2019). Pembelajaran Problem Solving Terintegrasi Phet: Membangun Pemahaman Konsep Listrik Dinamis. Kwangsan, 7(1).

Usman, H. (2017). Pengembangan Instrumen Tes untuk Mengukur Kemampuan Penalaran Matematis Siswa MTsN 1 Model Kota Makassar Universitas Islam Negeri Alauddin Makassar]. 